\title{
CAPACIDADE, DOTAÇÃO, TALENTO, HABILIDADES: UMA SONDAGEM DA CONCEITUAÇÃO PELO IDEÁRIO DOS EDUCADORES
}

\author{
Zenita Cunha Guenther* \\ Carina Alexandra Rondini* *
}

RESUMO: Embora o escopo deste trabalho seja de origem teórica, relata um estudo exploratório que busca situar a base de conceituação em Educação Especial para alunos Dotados e Talentosos, no Brasil, captando as definições compreendidas por profissionais da educação pela sondagem de sua opinião sobre que termos e expressões são usados, com que significados e em que situações. Os sujeitos incluíam 80 educadores interessados ou envolvidos na área (Grupo A) e 107 professores da rede pública no interior de São Paulo (Grupo B). Há poucas diferenças de opinião entre os sujeitos, nos dois grupos, com algumas exceções, principalmente em questões relacionadas a nível de conhecimento e familiaridade com referencial teórico. Ambos os grupos indicam conceituação confusa, notadamente para os termos oficiais, superdotação e altas-habilidades; a maior carga de rejeição e exploração na mídia é alocada a superdotação. Os conceitos alta capacidade, alto desempenho e dotação são definidos em consonância com o referencial básico, que diferencia capacidade natural de capacidade adquirida; Talento reflete a ambiguidade encontrada na área, referindo-se, ao mesmo tempo, a capacidade natural e capacidade adquirida.

Palavras-chave: Dotação. Talento. Superdotação. Altas Habilidades.

* Doutora em Education Foundations Psychology pela University of Florida. E-mail: zcguenther@gmail.com

* * Doutora junto ao Departamento de Psicologia Experimental e do Trabalho da Faculdade de Ciências e Letras, Universidade Estadual Paulista (UNESP). E-mail: cmarretto@yahoo.com.br 


\section{ABILITY, GIFTEDNESS, TALENT, SKILLS: \\ A PROBE INTO THE WAY THESE CONCEPTS ARE CONCEIVED, IN TEACHER'S MINDS}

ABSTRACT: The present study, while arising from a theoretical basis, is nonetheless, an exploratory study that attempts to identify the Basic Concepts of Special Education for is gifted and talented students of Brazil. The definitions and notions understood by the subjects, all professionals in the field of education, are captured by probing them, about their opinions on which terms and expressions are commonly used, with which meanings, and in which specific settings. The sample is comprised of 80 educators studying or involved within the area, (Group A), and 107 regular school teachers from a state school system in São Paulo State (Group B). Very few differences of opinion are registered between the two groups, save a few exceptions, mainly in relation to a knowledge of, and familiarity with, the theoretical framework. Both groups indicate conceptual confusion, in particular with the following official terms: super-giftedness and highly-skilled, with the largest rejection load (erroneous understanding) and also the highest media exploitation being allocated to the term, super-gifted. The concepts high ability, high performance and giftedness are defined according to the theoretical framework which differentiates natural ability from acquired ability; The word talent reflects the ambiguity encountered in the area, being referred to, at the same time, as natural ability and also as acquired ability.

Keywords: Giftedness. Talent. Super-giftedness. Highly Skilled.

\section{Um cenário conceitual confuso}

Um problema permanente na área da educação, em nossos meios, é a desconfortável diferença entre o conhecimento existente e a prática diária nas escolas. A maior parte do saber acumulado pela pesquisa científica, mesmo quando disponível aos profissionais da educação, permanece ao nível de discussão, publicações e comunicação em meios acadêmicos. Tal conhecimento não chega ao destino final, a sala de aula, e os professores não parecem ver relação entre o que se estuda em "Ciência da Educação" e o que acontece, de fato, no trabalho diário com os alunos. Atualmente, é notável em todo o mundo o interesse pela área de educação especial, para desenvolver capacidade e potencial nos escolares, e a literatura cresce a cada ano, mas esse conhecimento não parece estar influenciando muito a prática educacional, no Brasil (CUPERTINO, 2008; PERIPOLLI et al., 2009). Alguns estudos não relacionam dificuldades encontradas na prática à fragilidade de conhecimento, mas à presença de "[...] mitos sobre o superdotado (sic) freqüentes em nossa sociedade" 
(MONTE; SANTOS, 2004); e parece haver fé na improvável invenção de um "conceito geral", incluindo construtos associados à capacidade e à aptidão, às aprendizagens adquiridas, aos atributos pessoais e do ambiente (POCINHO, 2009).

É compreensível que, mesmo quem busca, na literatura internacional, bases científicas para sua prática encontre dificuldade em lidar com conceitos demasiadamente amplos e superpostos, como dotação, capacidade elevada ou talento. Mas, em nossos meios, além dessa dificuldade, adotamse termos e combinações de definição própria, como superdotação-barraaltas habilidades, em documentos oficiais, publicações e traduções (ao final, lista de documentos oficiais consultados), que extravasam para a mídia e vão se popularizando pela frequência do multiuso. Porém, um cenário assim confuso dificulta a compreensão dos conceitos, o que se reflete no dia a dia escolar, inibindo e obscurecendo esforços para identificação e provisão de condições educacionais favoráveis aos alunos dotados e talentosos (GUENTHER, 2010).

\section{Indefinições tradicionais}

A temática envolvendo conceituação de dotação humana, que vinha se arrastando ao redor do debate hereditariedade vs. ambiente, com argumentos embasados mais em ideologia do que conhecimento, não resistiu à autoridade do saber construído nas áreas da genética e neurociência. Por via desses estudos, aprofunda-se a área, abordando-se diferenças de desempenho que somente podem ser compreendidas com base em diferenças individuais genéticas, não hereditárias. Crawford (1979) observou que muitas pessoas associavam características genéticas com determinismo, e ambientais, com liberdade de escolha, mesmo após estabelecida a existência de hábitos e atitudes adquiridos no ambiente cultural que são extremamente resistentes à mudança. O geneticista Plomin (1983), que demonstrou como muitas características herdadas são modificáveis e características adquiridas são profundamente resistentes a mudanças, aponta a dificuldade em sacudir a falsa noção de que diferenças genéticas começam antes do nascer e permanecem imutáveis. No cenário geral, três autores se completam nos estudos para esclarecer essa questão, especificamente no que se refere à presença de capacidade elevada: Angoff 
(1988), Howe, Davidson e Sloboda (1998) e Gagné (1999). Pelos estudos revistos e analisados por esses pesquisadores, estabeleceu-se que aptidão indica capacidade natural, própria do indivíduo, enquanto desempenho refere-se a competências adquiridas por aprendizagem intencional, ensino e treino.

\section{Capacidade, aptidão e desempenho}

O termo aptidão (em inglês aptitude), geralmente, vem acompanhado do advérbio "para", acrescido de um campo de ação, implicando necessariamente a noção de potencialidade, p. ex: aptidão para línguas, para futebol, para matemática, para oratória... Uma importante dimensão do conceito de aptidão tem a ver com a diferenciação entre os construtos aptidão e desempenho - o que conduziu à investigação focalizando as medidas de aptidão separadas das medidas de desempenho. Angoff (1988), considerado o mais articulado entre os autores nessa temática (GAGNÉ, 2009), ao aprofundar estudos sobre aptidão e desempenho, enfrentou dificuldade em estabelecer distinções entre esses dois conceitos e concentrou-se em analisar a maneira como os construtos aptidão e desempenho são medidos, partindo do princípio de que aí está a base efetiva da conceituação. Pela análise profunda dos resultados alcançados por medidas de aptidão e por medidas de desempenho indica as seguintes diferenças entre esses construtos:

\section{QUADRO 1}

Aptidão e desempenho: Características diferenciais

Aptidão

Crescimento lento

Aprendizagem informal

Resistência a estímulos

Maior substrato genético

Maior conteúdo geral

Mais aprendizagem "velha"

Maior faixa de generalização

Maior poder de prospecção e previsão

Maior utilidade para avaliação ampla
Desempenho

Crescimento rápido

Ensino formal

Susceptibilidade a estímulos

Maior componente de prática

Maior conteúdo circunscrito

Mais aquisições "novas"

Estreita faixa de transferência

Maior uso retrospectivo

Limitada a indivíduos ensinados 
Ambos, aptidão e desempenho, são, em essência, capacidades passíveis de serem desenvolvidas, como qualquer traço mental que se modifica com o passar do tempo, mas Angoff identifica características inerentes ao processo de desenvolvimento associado a cada construto:

(1) Melhoria no desempenho é alcançada imediatamente, por ensino e exposição a um conteúdo ou área; e aptidão cresce vagarosamente, como consequência da vida diária, seja independente, seja relacionada a alguma forma de aprendizagem formal, mas o desenvolvimento se dá por meio de aprendizagem informal não diretamente controlada.

(2) Aptidão tende a resistir a esforços para apressar o desenvolvimento; e desempenho responde a tais esforços.

(3) Notas em provas de desempenho medem quantidade de aprendizagem passada; e testes de aptidão buscam previsão de possibilidades para aprendizagem futura.

(4) Medidas de aptidão podem ser generalizadas para uma faixa ampla da população; e conhecimento e habilidades associados ao desempenho se aplicam a uma área restrita.

(5) Medidas de desempenho são baseadas em faixas estreitas de conteúdo conhecido ou estudado; e medidas de aptidão exploram domínios mais ampliados, presumivelmente dentro de um contexto cultural comum, acessível a todos os indivíduos.

(6) Aptidão é, por natureza, orientada para a prospecção, com implicações para aprendizagens futuras; desempenho é, por natureza, retrospectivo e voltado para aprendizagens passadas.

Outro estudo compreensivo, envolvendo conceituação, vem de Howe, Davidson e Sloboda (1998), que põem em dúvida a existência de dotes ou dons naturais, propondo o que chamam talento inato, com cinco características: (1) Originado em estruturas geneticamente constituídas; (2) Efeitos completos podem não se evidenciar ao início da vida; (3) Indicações de talento na infância podem dar base para previsão de excelência futura; (4) Existe somente em uma minoria da população; (5) É relativamente específico a determinado domínio.

Finalmente, Françoys Gagné integra esses resultados aos estudos preparatórios à proposição do Differentiated Model of Giftedness and Talent (DMGT), uma teoria-modelo de transformação de capacidade natural (dotação) em competências (talentos), com conceituação diferenciada para cada um dos construtos. 


\section{Capacidade natural - o construto}

Gagné (2005) é o autor que melhor conseguiu traçar uma configuração diferenciada desses conceitos, estabelecendo distinção entre os construtos dotação e talento. Estudou, com admirável dedicação, toda a literatura básica na área e áreas adjacentes, e sua busca de termos prima por absoluto cuidado em estabelecer o sentido exato para cada palavra, referente a cada conceito. Reconhece na expressão Capacidade natural (natural ability) um construto básico à compreensão profunda das diferenças individuais: capacidade relaciona-se ao poder físico ou mental de "fazer alguma coisa", ou seja, aprender e agir, mas não é o mesmo que traços pessoais, os quais indicam outros atributos, configurando a vasta área de construtos de personalidade. Assim, diferencia as características de capacidade alta (bigh ability), a que chama "dotes" (gifts) ${ }^{1}$, expressos, geralmente, em domínios traçáveis a funções cerebrais:

(1) Capacidade natural tem raízes diretamente originadas na dotação genética da pessoa, todavia, a influência genética nas diversas capacidades não denota efeitos de um gene específico, e sim a propensão probabilística de sistemas multigenes (PLOMIN, 1998).

(2) Capacidade natural atua como potencial para ação e elementos que vão constituir as competências, portanto, antecede o desempenho.

(3) A capacidade natural se desenvolve informal e lentamente, tanto pelo processo de maturação quanto pelo uso indiferenciado na vida diária, por conseguinte, todas as capacidades naturais são mais resistentes a mudanças do que competências; maturação é um processo relacionado às raízes genéticas, e o viver diário explica, ao mesmo tempo, o desenvolvimento espontâneo e o ritmo interno, próprio, em que isso acontece.

(4) Capacidade natural atua em qualquer campo de ação, é essencialmente independente de áreas ou conteúdos e está disponível para qualquer ramo de atividade propiciado pelo ambiente. Dessa forma, não seria apropriado dizer dotação musical, dotação atlética, dotação acadêmica porque indicam campos específicos de atividades dependentes de aprendizagem, exercício e treino.

(5) Capacidade natural tem poder de previsão em relação ao nível de desempenho sistematicamente desenvolvido; o paralelismo entre "pares de palavras", como dotação e talento, aptidão e desempenho, potencial e 
produção, traz em si a implicação de correlação entre eles; por exemplo, alto potencial (dotação) leva a um alto nível de produção (talento).

(6) Como consequência, o nivel de capacidade natural impõe, necessariamente, restrições ao nível esperado de competência, isto é, altos níveis de capacidade (dotes) aumentam a probabilidade de alto nível de competência no desempenho e vice-versa. Assim, não se deve dizer capacidade e talento porque essa expressão pode sugerir que talentos não são capacidades. Por outro lado, o termo capacidade não substitui diretamente, nem o termo potencial, nem desempenho, porque é necessário especificar o tipo de capacidade, adicionando um adjetivo descritivo (capacidade intelectual, capacidade física...). Essa noção constitui a base da diferenciação da capacidade humana em domínios específicos.

Há autores que se opõem à ideia de que alguns tipos de capacidade sejam capacidades naturais (CHARNESS, 1998; ERICSSON, 2003; LEHMANN, 1998; STARKES; HELSEN, 1998; TESCH-RÖMER, 1998); ao passo que outros chamam dotação de talento inato (ERICSSON; RORING; NANDAGOPAL, 2007; HOWE; DAVIDSON; SLOBODA, 1998), o que expressa o mesmo conceito com outra palavra, agravando o observado caos conceitual (GAGNÉ, 2009).

\section{Dotação (em inglês, giftedness)}

Plomin (1998) salienta que, uma vez suficientemente estabelecida a resposta para as questões iniciais sobre se e quanto a constituição genética contribui para a existência de capacidade - pelos seus estudos, a resposta é afirmativa, quer dizer, contribui, sim, em elevada proporção -, a pesquisa está se aprofundando na exploração dos diferentes graus da capacidade enraizada na constituição genética. Ao alcançar o extremo da curva de distribuição, é inaugurado o estudo da dotação, referindo-se a elevado grau de capacidade natural.

A etimologia do termo dom como "dote" traz a ideia de um presente dado ao indivíduo, pelos deuses, pelos ancestrais ou pela natureza. Nesse particular, Gagné (2005) alerta para o perigo de se alargar demasiadamente o construto dotação para evitar diluir sua significação, uma dificuldade que vem sido observada em relação ao construto de inteligência, o que se verifica na noção de inteligências múltiplas, de Gardner (1983), 
inteligência emocional, de Goleman (1995), ou inteligência do sucesso, de Sternberg (2003).

Embora seja fácil compreender capacidade natural como predisposição ou tendência, não se encontrou termo mais apropriado para dotação, dom, dote. Faz algum sentido que, em meios acadêmicos, pensem em dotação como "capacidade para raciocinar"; no mundo das publicações, como "capacidade de criar", nos autores de ficção; e no mundo dos esportes, como "capacidade física", nos atletas... Isso revela que, a não ser pela visibilidade do desempenho notavelmente acima da média, dotação e talento compartilham um conceito de ordem superior, o conceito de capacidade, compreendido como o poder de aprender e fazer alguma coisa física ou mental. Por ser um termo abrangente, capacidade remete tanto ao conceito de dotes quanto ao de talentos, e não especificamente a um ou outro. Outra dificuldade de conceituação é estender o termo dotação para características que não concernem a uma capacidade. Capacidade significa poder de aprender e potencial para ação. Outras características humanas existem, mas pertencem à ampla gama de construtos de personalidade, que correspondem a estilos de comportamento (MCCRAE et al., 2000). Assim, expressões como dom do otimismo, dom da religiosidade (PIECHOWSKI, 2003), ou preferências pessoais, como gostar de conviver, preferir matemática, tomados como sinais de capacidade, podem gerar ambiguidades desnecessárias.

\section{Dotação e inteligência}

Os construtos de inteligência e de dotação parecem estar associados, na mente de muitos especialistas em educação para dotados, de sorte que há mais pesquisa sobre o domínio intelectual do que todos os outros domínios combinados, o que leva à distorção de ambos os conceitos. Tal limitação é amplamente demonstrada na literatura, com preocupação geral sobre a distorção conceitual que acarreta (PLOMIN, 1998). Inteligência é um domínio de capacidade entre outros, sendo possível haver dotação em um domínio, por exemplo, dotação física ou socioafetiva, sem haver necessariamente dotação em inteligência. 


\section{Prodígios}

Crianças-prodígio recebem muita atenção por exibirem extrema facilidade em aprender determinada habilidade, o que leva também a associar prodígio com dotação, já que dotação compreende essencialmente facilidade e rapidez de aprendizagem naquele domínio em que existe capacidade superior. Porém, estudos longitudinais evidenciam que o prodígio pode ser apenas expressão de precocidade, e não efetivamente sinônimo de dotação, pois há mais crianças precoces que a probabilidade esperada de dotação, enquanto muitas pessoas dotadas não foram prodígios ou sequer precoces. A noção de prodígio seria mais bem-considerada como extrema precocidade no grau e no ritmo de maturação do aparelho nervoso central do que como sinal de potencial elevado.

\section{Talento (em inglês, talent)}

A confusão conceitual observada sobre o sentido do termo talento parece dever-se à ambiguidade no significado comum da palavra, quando usada para descrever ambos: alto potencial e alto desempenho. Etimologicamente, talento se referia a uma medida de peso, portanto, sem associação com capacidade humana. Curiosamente, os talentos, mesmo como medida de peso, não tinham valor constante, permitindo pensar que eram distribuídos com base no desempenho do indivíduo, em dada atividade, o que depende da sua capacidade para desempenhar. Essa ideia é compatível com o construto atual talento (GAGNÉ, 2009).

O termo talento tem constantemente criado incertezas, pela falta de distinção clara entre capacidade e desempenho. Ericsson, Roring e Nandagopal (2007) resumem o conceito de excelência, também associado a desempenho superior, em vontade e exercicio intencional que, de fato, têm relevante papel na emergência e no desenvolvimento de um talento. Desse modo, pode-se compreender o uso de talento e excelência sob o mesmo conceito: alto nível de desempenho em um campo de atividade. 


\section{Competência (em inglês, competence)}

Parece ser um termo mais abrangente para expressar aquisição de conhecimento acoplado a habilidades operacionais, de maneira que tanto como substantivo (competência) quanto como adjetivo (competente) descreve um nível de desempenho que ultrapassa o mínimo requerido para a ação comum. Competência se refere a um amplo universo de capacidades, intencional e diretamente treinadas em habilidades. A noção de raízes genéticas diretas e indiretas expressa bem a diferença entre capacidade natural e competências; p. ex., as raízes genéticas de competência acadêmica são indiretas, elas se originam nas relações entre inteligência (um domínio de capacidade natural) e desempenho acadêmico, uma competência adquirida (PLOMIN; PRICE, 2003). As diferenças individuais em capacidade natural dão origem a diferenças individuais em desempenho acadêmico.

\section{"Expertise"}

É usado em português, sem tradução. Experté um termo utilizado para identificar pessoas que desempenham confiavelmente, em níveis elevados e previsíveis de qualidade (ERICSSON; RORING; NANDAGOPAL, 2007). Nesse sentido, pode-se pensar em experts em mecânica, em jardinagem, em enfermagem, em artes gráficas... Mas, para se falar em um expert jornalista, professor ou psicólogo, por exemplo, haveria dificuldade com a condição de desempenho superior constante e reproduzivel, destacado pelos autores, pois quanto mais seletivo for o conceito, maior a dificuldade em fazer previsões sobre aplicabilidade.

\section{Habilidade/s (em inglês, skill/s)}

Termo empregado para descrever um amplo leque de competências treinadas: habilidade verbal, habilidades culinárias, habilidades sociais, habilidades de ensino, enfim, há centenas de tipos diferenciados de habilidades. Como vem explicitado nos tradicionais exemplares de Manual de Habilidades, empregados na orientação vocacional, é possível estender o sentido comum do termo, associado ao desempenho de uma ação concre- 
ta e física, para o domínio das operações mentais e, por exemplo, falar em habilidades de raciocínio, de memória ou perceptividade social. Todavia, é importante manter em mente que esse termo é atinente a resultados de algo aprendido e/ou treinado, intencionalmente. $\mathrm{O}$ termo babilidade não expressa facilmente a noção de conhecimento, um elemento necessário a situações mais complexas de aprendizagem. Se fosse possível definir capacidade natural em termos de habilidades, esse termo não se aplicaria mais a desempenho aprendido. Talvez seja possível entender o termo habilidades, em um conceito geral, incluindo dois componentes: conhecimento e habilidade, ou seja, fatos e ações. Nesse caso, seria possível aferir um elemento de capacidade natural (aptidão) e outro de capacidade treinada (competência), aceitando a inclusão do termo habilidade no conceito de dotação como capacidade natural expressa em desempenho treinado. Entretanto, aprofundando essa análise, esbarra-se na questão de que o conbecimento não é uma capacidade natural, mas também algo adquirido.

Dotação e talento representam manifestações notáveis de capacidade. Como dotação representa essencialmente "capacidade em potencial", o melhor termo para expressar essa noção é, sem dúvida, capacidade natural. No caso dos talentos, estamos tratando de capacidades desenvolvidas, que resultam de períodos intensos de aprendizado, treino e prática.

\section{Peculiaridades do cenário brasileiro}

De fato, pode-se observar o cenário geral relativamente obscuro na conceituação de dotação e talento, dois construtos básicos à educação especial para alunos mais capazes, de sorte que pode trazer perplexidade, a quem está estudando um assunto, verificar que a utilização de duas palavras diferentes não significa presença de dois conceitos diferenciados. Mas, ao que parece, o caos é agravado no cenário brasileiro com instruções oficiais e publicações acadêmicas que também dificultam clarear os conceitos, por usar uma terminologia própria, com termos vagos unidos por barras sem significação específica, como superdotação-barra-altasabilidades, substituindo ou, no mínimo, confundindo os construtos estabelecidos pela pesquisa (cf. legislação referenciada a seguir).

A posição deste artigo, com base no referencial exposto, apoiase no ideário estabelecido por Angoff (1988), Plomin (1998), Howe, 
Davidson e Sloboda (1998), sintetizado por Gagné (1999), estabelecendo diferenciação entre capacidade natural e adquirida. Sob essa visão, talento é um construto diferenciado e não deve ser empregado como complemento ou sinônimo de dotação, embora nossa legislação tome liberdade para usar esses termos a seu próprio juízo: "[...] educaşão especial se destina às pessoas com necessidades especiais no campo da aprendizagem, originadas quer de deficiência física, sensorial, mental ou múltipla, quer de características como altas habilidades, superdotação (sic) ou talentos" (BRASIL, 2001, grifo nosso). Às vezes, a finalidade é ditar medidas de natureza pedagógica, como: "O AEE é destinado aos alunos [...] altas habilidades, superdotação (sic) ou talentos deve integrar a proposta pedagógica da escola, envolver a família..." (BRASIL, 2009b). A posição do presente estudo é que tais medidas fogem ao terreno de "estabelecer políticas públicas" e avançam para o campo da conceituação científica.

\section{Traduções e interpretações}

Pelo que se pode inferir, a confusão na terminologia brasileira parece ter-se iniciado pela inserção do prefixo super- na tradução dos termos americanos giftedness e gifted, que significam, literalmente, dotação (gift: prenda, presente; ness: essência, natureza) e dotado (tem dotação). O termo superdotação foi mal-aceito nos meios educacionais. Para amenizar o efeito, buscou-se a expressão inglesa high ability, em português, capacidade elevada, a qual, mal traduzida para altas habilidades, perdeu a essência do conceito.

Na prática escolar, pode-se observar como esse caos é um complicador maior que simples dissidência semântica, pois conceitos malassentados e imprecisão de termos geram insegurança, dificultando posicionar o trabalho educativo. Tal fato é enfatizado por autores que indicam essa área como praticamente inexistente, embora presente em documentos legais (CUPERTINO, 2008). Curiosamente, isso não é interpretado como carência de conhecimento, mas efeito de mitos: "[...] uma possível explicação para este cenário são os vários mitos sobre o superdotado (sic) freqüentes em nossa sociedade que constituem entrave à provisão de condições favoráveis à sua educação" (MONTE; SANTOS, 2004, p. 11, grifo nosso). Nota-se também a esperança de improvável "adoção de um conceito geral", incluindo construtos associados à capacidade e aptidão, atributos pes- 
soais e aprendizagens adquiridas: "Importa adotar um conceito de sobredotação que não se confina à inteligência abstrata ou à aprendizagem escolar, passando, por exemplo, a incluir-se também, as habilidades sociais, a liderança ou a criatividade, variáveis mais associadas à personalidade, à motivação e aos próprios contextos de vida" (POCINHO, 2009, p. 4).

Pelo que se constata, no corpo de pesquisa atual, tal esperança parece cientificamente improvável, por não haver referencial teórico que a sustente. Por conseguinte, pode-se induzir que o cenário brasileiro parece ignorar, ou pelo menos minimizar, a aceitação cada vez mais difundida à conceituação adotada como base para o presente estudo: dotação - designando posse e uso de notável capacidade natural, em pelo menos um dominio de capacidade humana; talento-designando desempenho superior, conhecimento aprendido, mestria, habilidades desenvolvidas sistematicamente, implicando alto nível de realização em algum campo de atividade humana. Esses conceitos têm três características em comum: a) referem-se a capacidades humanas; b) são normativos, por apontar indivíduos que diferem da norma; c) indicam pessoas "fora do normal", por produção notavelmente superior. Tais características ajudam a entender por que alguns dicionários, às vezes, definem "dotação" como "talento" e vice-versa.

\section{Palavreado}

A preocupação com precisão de termos para expressar construtos científicos é relevante, pois o conhecimento é produzido em diversas culturas, publicado em diversas línguas, e as traduções e interpretações são geralmente um empecilho para a comunicação precisa. Além disso, há ocorrências em que o mesmo assunto é estudado em vários lugares, cada autor sente que está "descobrindo" algo novo e atribui-lhe um nome, para, depois, verificar que as palavras são diferentes, mas a noção conceitual é a mesma. No Brasil, Helena Antipoff, desde que aqui chegou, em 1929, com publicações e estudos em várias línguas, deu exemplo de extremo cuidado na escolha de termos educacionais, mormente na área da educação especial. Foi ela que introduziu o termo "excepcional", hoje usado em todo o mundo, para designar alunos com necessidades especiais diferentes da norma do grupo. Por sua influência, as primeiras menções à educação para alunos mais capazes, em nosso país, empregaram supranor- 
mal como oposto linguístico a infranormal, então uma das alternativas para substituir termos pejorativos como idiota ou retardado. Todavia, em vista de infranormal ter sido abandonado, também o foi o supranormal. Nas décadas de 1950 e 60, com a expansão trazida à educação para dotados nos Estados Unidos, na sequência da Guerra Fria, houve um número de publicações em todo o mundo, e as traduções entraram no cenário da terminologia educacional. Localiza-se por essa época o surgimento dos termos superdotado e superdotação, em nossos meios.

Superdotação - tanto quanto se pode verificar, não existe uma concepção teórica à base desse termo: ele não está em nenhuma definição utilizada em estudos científicos ou na literatura da área, e não é usado em nenhum lugar do mundo, a não ser no Brasil e talvez em algumas versões de publicações brasileiras em espanhol. No cenário brasileiro, é uma peculiaridade, porque está definido em instruções oficiais e algumas publicações no meio acadêmico, inexplicavelmente acoplado a conceitos teoricamente diferentes, por meio de barras, como em superdotação/altas habilidades (sic).

Boa dotação - essa expressão foi sugerida por Helena Antipoff, na década de 1960, na tentativa de amenizar o impacto da rejeição ao superdotação. É algumas vezes empregada na literatura, em estudos focalizando diferentes graus de capacidade elevada, com as mesmas bases conceituais de dotação. Como seguidora de Helena Antipoff, empreguei esse termo por vários anos (provavelmente até 2005-06), porém, ao perceber que a raiz do problema não estava no grau conceitual de dotação, mas na tradução do termo giftedness, abandonei definitivamente o uso.

Altas habilidades - essa combinação de palavras é uma expressão que também não tem referencial teórico, portanto não é usada em nenhum outro lugar do mundo. Conceitualmente, o termo habilidade/s se relaciona a resultados de algo aprendido e/ou treinado intencionalmente. É geralmente associado a bom desempenho no domínio da capacidade física, estendido a certas operações mentais. Todavia, a inserção do qualificativo altas modifica o alcance do conceito, ressaltando a tradução inapropriada da expressão bigh ability, literalmente alta capacidade.

Alta capacidade - tradução literal e correspondente conceitual de high ability, alta capacidade refere-se à presença de elevado grau de capacidade natural na constituição do plano genético do indivíduo, estando assim à base das diferenças individuais. Capacidade como conceito indica 
poder físico ou mental de aprender e fazer alguma coisa. A qualificação alta ou elevada é necessária ao conceito de dotação porque o grau de capacidade é relacionado ao grau de profundidade e rapidez com que se opera o poder de aprender. Quando esse grau alcança pelo menos dois desviospadrão acima da média, na curva de probabilidade de distribuição, temos base para compreender a dotação.

Dotação - é um construto representativo do extremo superior na distribuição de capacidades humanas, nos diversos domínios, portanto, é um termo diretamente relacionado à conceituação de capacidade natural. A etimologia da palavra, nas várias línguas, como em português dom ou dote, traz à mente a ideia de presente, doação. A dotação, como capacidade natural, é invisível, mas pode ser inferida por meio de canais de expressão providos pelo ambiente.

Talento - é um termo de utilização diversificada, tanto na mídia quanto em educação, com algumas vantagens, mas com a desvantagem da conceituação difusa, mesmo na literatura técnica, na qual pode ser visto ao mesmo tempo como "uma capacidade natural", o que, efetivamente, está à sua base, ou como uma expressão de desempenho superior aprendido, que é sua raiz conceitual. Deve-se a Gagné a proposição de diferenciar o conceito de talento - desempenho superior, de dotação - capacidade superior. A crescente preferência por essa conceituação tem razões compreensíveis: a capacidade humana faz parte da constituição genética, por conseguinte, está em toda a humanidade, em certos domínios e, em diferentes graus, nos indivíduos. Talento é uma expressão externa, diretamente relacionada ao que está disponível no ambiente; assim, apesar de haver somente alguns domínios de capacidade (Gagné indica cinco: inteligência, criatividade, capacidade socioafetiva, capacidade física e capacidade perceptual), há, literalmente, inúmeros talentos, como se vê pelo uso da palavra: talento culinário, talento informático, mecânico, artístico, indicando concretamente diferentes áreas de desempenho; encontra-se também em certas combinações não diretamente relacionadas a um tipo de desempenho, tais como talento social ou talento criativo, sempre com implicação de desempenho em grau superior. 


\section{Em resumo}

Numa visão panorâmica envolvendo termos, conceitos e ideias utilizados na área de educação para dotados e talentosos, podese destacar:

1. Capacidade natural (ANGOFF, 1988; GAGNÉ, 2009; PLOMIN, 1998)

Designa uma condição que antecede desempenho, originada em predisposições existentes no plano genético, diferenciando capacidade natural (origem genética) de capacidade adquirida (originada em aprendizagens no ambiente).

Dotação é um conceito quantitativo referente à posição de, pelo menos, dois desvios-padrão acima da média na curva de distribuição, em um ou mais domínios de capacidade.

diferenciado.

Aptidão indica dotação para uma área ou campo de ação

Talento inato é concernente ao notável grau de capacidade originada no plano genético, sem diferenciar de capacidade adquirida no ambiente (ERICSSON; RORING; NANDAGOPAL, 2007; HOWE; DAVIDSON; SLOBODA, 1998).

2. Capacidade adquirida (ANGOFF, 1988; GAGNÉ, 2009; PLOMIN, 1998)

Sinaliza nível superior de desempenho, condicionado à presença de capacidade natural elevada e desenvolvido por influência de forças ambientais, ensino e prática.

Talento indica desempenho extraordinário em um campo de ação definido, dependente do grau de capacidade genética, condicionado a ensino, exercício e prática (ANGOFF, 1988; GAGNÉ, 2009).

Competência remete a grau satisfatório de desempenho em alguma área ou campo de ação definido, resultado de aprendizagem intencional, exercício e prática (PLOMIN; PRICE, 2003).

"Expertise" refere-se a um grau superior, constante e previsível de desempenho em alguma área ou campo de ação definido (ERICSSON; RORING; NANDAGOPAL, 2007).

Excelência relaciona-se a alto nível de desempenho em 
campo de ação definido, desenvolvido por vontade e exercício intencional (ERICSSON; RORING; NANDAGOPAL, 2007).

\section{Variações}

Inteligências múltiplas referem-se a diferentes molduras específicas ao trabalho mental, sem diferenciar origem ou natureza genética de aprendizagem ambiental (GARDNER, 1983).

Superdotação/altas habilidades - termos usados no Brasil, incluídos em documentos oficiais da área da educação (ver legislação a seguir referenciada).

O referencial de base para este estudo integra a posição que distingue capacidade natural, predisposta no plano genético e desenvolvida informalmente no cotidiano, de capacidade adquirida, captada no ambiente, desenvolvida por ensino intencional, exercício e prática.

\section{Metodologia}

O presente estudo partiu do interesse em compreender o ideário conceitual de domínio do professorado de nível básico, na tentativa de situar melhor a resistência da escola em relação ao tema. O movimento de inclusão vem subsidiando a contínua oferta de cursos e seminários em educação especial, e a maioria deles inclui intervenção sobre o aluno dotado. Pelo Decreto n. 5.151, de 2004, foram implantados os chamados NAAHS - Núcleos de Atividades de Altas Habilidades/Superdotação (sic), com o objetivo de "estabelecer uma política" para a área. Apesar desse esforço, com ampla divulgação na mídia e constante demanda das famílias, não se nota diferença na posição da escola, nos últimos 20 ou 30 anos, continuando a área "[...] predominantemente ignorada, quando se trata da prática educacional [...], salvo em casos isolados muito raros" (CUPERTINO, 2008).

A partir de questões levantadas principalmente em eventos e cursos, somadas a perguntas diretas sobre planos de intervenção educativa, foram observados dois pontos focais de resistência, nos professores: a) rejeição generalizada, levando à negação de capacidade superior nos 
alunos; b) crítica à superficialidade e à incoerência na terminologia. Por outro ângulo, na tentativa de colocar a especialistas da área questões referentes à fragilidade dos conceitos e dificuldades com terminologia, percebese: a) fidelidade a autores, aparentemente sem preocupação maior com a pesquisa básica; b) consenso em aceitar o que "reza" a legislação; c) argumentos de que este ou aquele termo causam rejeição.

Pela análise de impressões colhidas na literatura e na orientação oficial, situações de interação em mesas-redondas, seminários, eventos e conversas informais com especialistas sobre a posição dos professores atuando com as crianças, foram levantadas as seguintes perguntas: i) Que termos e expressões são usados, com que significados e em que situações?; ii) Qual o nível de consenso no uso dos diversos termos e expressões?; iii) até que ponto o nível de rejeição é associado a que termos específicos?

\section{Instrumento de sondagem}

Pelo estudo de documentos e programas de eventos, e pela interação com equipes técnicas em serviço nas escolas e nos órgãos oficiais de educação, levantou-se um palavreado comum veiculado nos meios escolares: Altas habilidades, boa dotação, alta capacidade, desempenho notável, dotação, superdotação e talento. Integrando os dados e impressões colhidas nos meios escolares com noções derivadas do referencial teórico, foram construídas dez afirmações sobre significados associados ao palavreado:

Em relação à base conceitual: a pessoa traz consigo ao nascer; é desenvolvido pelo ambiente; depende de ensino e treino; é de compreensão fácil.

Sobre consenso de uso: é apropriado ao meio escolar; está na legislação e em documentos oficiais; é explorado pela mídia.

Opinião desfavorável: Não é uma noção muito clara; leva à rotulação; causa maior rejeição.

Com esses elementos, foi composto um instrumento de sondagem, pedindo-se aos sujeitos para opinar que termo ou termos poderiam ser aplicados a cada uma das afirmações do questionário (Apêndice 1). 


\section{Casuística e coleta de dados}

O caminho visualizado para abordar a realização deste estudo implicou procurar colher dados diversificados, de fontes variadas, nas situações as mais diversas possíveis. Para tal, as pesquisadoras levaram cópias do questionário aos eventos de que participaram durante o segundo semestre de 2009, solicitando aos presentes que quisessem para preenchê-lo e devolver ao final da sessão. Assim, foram reunidos 80 questionários, em diversos lugares de Minas Gerais e São Paulo, nas seguintes situações: duas universidades federais, durante apresentação de teses; três eventos locais sobre inclusão, para professores e estudantes de Pedagogia e licenciaturas; um curso de especialização sobre o tema; reuniões de professores trabalhando com crianças dotadas e talentosas; educadores visitando um Centro Comunitário para Dotados e Talentosos. Essa amostra constituiu o Grupo A - educadores envolvidos ou interessados na área. $\mathrm{O}$ grupo foi designado "interessado" porque em todas as situações as pessoas estavam ali espontaneamente, por já estudar o tema, trabalhar na área ou procurando se esclarecer, em princípio sem pressão externa ou objetivo paralelo. Nas sessões de defesa de tese, nas quais poderia haver convidados, foi explicado o objetivo do estudo, podendo a pessoa optar por não responder. Implicitamente, poder-se-ia esperar desse grupo algum conhecimento sobre os conceitos e termos empregados.

O Grupo B foi formado por 107 professores do Ensino Fundamental que trabalham no sistema público, independentemente de estarem interessados no assunto. A eles foi enviado o questionário, no início de 2010, pela Secretaria Municipal da Educação e Diretoria Regional de Ensino, solicitando que, voluntariamente, respondessem a ele e devolvessem, em duas semanas. Implicitamente, não se esperava desse grupo interesse ou conhecimento sobre o assunto, a não ser por acaso. 


\section{Resultados e discussão}

O interesse concentrou-se em sondar a configuração geral dos conceitos e noções atuando no ideário de educadores que se interessam pela área e dos professores regulares de nível básico:

\section{Conceituação básica}

Foram associadas à conceituação básica as seguintes afirmações: traz ao nascer, é desenvolvido pelo ambiente; depende de ensino e treino; é fácil de compreender.

A referência conceitual a essa pesquisa apoia-se na posição teórica que distingue capacidade natural prevista no plano genético (dotação, alta capacidade), desenvolvida informalmente no cotidiano, de capacidade adquirida intencionalmente por influência do ambiente (talento, desempenho superior). Os resultados estão assim configurados:

\section{QUADRO 2}

Conceituação básica - Resultados

\begin{tabular}{|c|c|c|c|c|c|c|c|c|c|c|c|c|c|c|c|c|c|c|c|c|c|c|c|c|}
\hline \multirow[b]{2}{*}{ Termo } & \multicolumn{3}{|c|}{ AH } & \multicolumn{3}{|c|}{ BD } & \multicolumn{3}{|c|}{ AC } & \multicolumn{3}{|c|}{ DN } & \multicolumn{3}{|c|}{ DT } & \multicolumn{3}{|c|}{ SD } & \multicolumn{3}{|c|}{$\mathrm{TE}$} & \multicolumn{3}{|c|}{ TOTAL } \\
\hline & A & B & $\mathrm{T}$ & A & B & T & A & B & T & A & B & $\mathrm{T}$ & A & B & $\mathrm{T}$ & A & B & T & A & B & T & A & B & $\mathrm{T}$ \\
\hline $\begin{array}{l}\text { Traz consigo } \\
\text { ao nascer }\end{array}$ & 6 & 9 & 8 & 6 & 4 & 5 & 5 & 9 & 7 & 2 & 2 & 2 & 47 & 19 & & 4 & 15 & 11 & 29 & 2 & 37 & 99 & 100 & 99 \\
\hline $\begin{array}{l}\text { Desenvolvido } \\
\text { pelo ambiente }\end{array}$ & 23 & 35 & 29 & 5 & 4 & 4 & 5 & 11 & 8 & 23 & 26 & 24 & 1 & 5 & 3 & 1 & 1 & 1 & 42 & 18 & 27 & 100 & 100 & 96 \\
\hline $\begin{array}{l}\text { Não é muito } \\
\text { claro }\end{array}$ & 19 & 14 & 15 & 25 & 27 & 26 & 6 & 7 & 7 & 6 & 7 & 7 & 8 & 24 & 18 & 32 & 22 & 26 & 6 & 2 & 3 & 102 & 110 & 100 \\
\hline $\begin{array}{c}\text { Depende de } \\
\text { ensino, treino }\end{array}$ & 24 & 36 & 33 & & 1 & & 2 & 13 & 12 & 31 & 35 & 34 & 6 & 3 & & 1 & 4 & 3 & 26 & 8 & 15 & 100 & 100 & 102 \\
\hline Total & 72 & 94 & 85 & 36 & 36 & 36 & 28 & 30 & 34 & 62 & 67 & 65 & 62 & 51 & 54 & 38 & 42 & 41 & 103 & 70 & 82 & 401 & 410 & 390 \\
\hline Md & 18 & 23 & 21 & 9 & 9 & & 7 & 7,5 & 8 & 15,5 & 17 & 16 & 15,5 & 13,5 & 13 & 9,5 & 10,5 & 10 & 26 & 17,5 & 20,5 & & & \\
\hline
\end{tabular}

AH: Altas Habilidades; BD: Boa Dotação; AC: Alta Capacidade; DN: Desempenho Notável; DT: Dotação; SD: Superdotação; TE: Talento; Md: média

Os resultados são semelhantes nos dois grupos, com exceção ${ }^{2}$ de Talento depender de ensino e treino, apontado pelo Grupo A, mas não pelo grupo B (pA $=0.261 ; \mathrm{pB}=0.078$; IC: [0.083 a 0.283], $\mathrm{p}=0.0003)$, e Dotação não ser um conceito claro para o Grupo B (pA = 0.080; $\mathrm{pB}=0.241$; IC: [0.068 a 0.253], $\mathrm{p}=0.0007)$. 
Termos Conceituados em coerência com o referencial: Dotação (traz ao nascer e não depende de treino) seguido de Desempenho notável (depende de ensino e treino e é desenvolvido pelo ambiente). O padrão de resultados captou o chamado erro comum (GAGNÉ, 2004) associado ao conceito de talento, como ambos: algo que se traz ao nascer e é desenvolvido pelo ambiente, certamente um reflexo da ambiguidade encontrada no contexto maior. Podem ser vistos como resultados coerentes com o referencial teórico para o conceito de habilidade (se se ignorar o adjetivo altas): Desenvolvido pelo ambiente e depende de ensino e treino.

Resultados não coerentes com o referencial teórico: Alta capacidade não indica ser entendida como parte do plano genético e tende a ser vista como algo que depende de ensino e treino, uma noção aplicável ao conceito de habilidade, mas não de capacidade. Idêntico padrão de respostas é verificado nos dois grupos de sujeitos. Isso possivelmente é uma indicação de que traduzir ability para habilidade pode estar dificultando a compreensão dos dois conceitos: capacidade natural, de origem genética, e habilidade, capacidade adquirida, por influência do ambiente.

Pontos conceituais sensíveis: O padrão geral indica falta de clareza na conceituação dos termos superdotação e boa dotação. Maior grau de sensibilidade é expresso por incoerência rondando a expressão altas habilidades, que, mesmo se conceituada como habilidade, é uma noção pouco clara em ambos os grupos, possível evidência de confusão conceitual associada à tradução do inglês ability. Entretanto, uma particularidade encontrada no Grupo B (professores do sistema) sugere similaridade na conceituação de dotação $(\mathrm{pB}=0.175)$ e superdotação $(\mathrm{pB}=0.230)$, possivelmente assimilando o termo como a legislação indica (IC: [0.025 a 0.085], $\mathrm{p}=0.0003)$.

\section{Consenso pelo uso}

Uma justificativa ao uso do palavreado adotado em nossos meios é haver "consenso", isto é, um acordo tácito de aceitação a essa terminologia. Para sondar até que ponto isso se verifica entre os professores, os itens apropriado ao meio escolar, usado pela legislação e documentação oficial e mais explorado pela mídia foram associados à indicação de consenso favorável ao uso. Foi acrescentado o item conceitual - fácil de compreender-, no sentido de possibilitar um tom geral favorável ao tema. Não havendo 
necessidade de coerência ou apoio teórico, qualquer indicação tem valor como opinião pessoal. Os resultados assim se configuram:

\section{QUADRO 3}

Opinião sobre consenso pelo uso

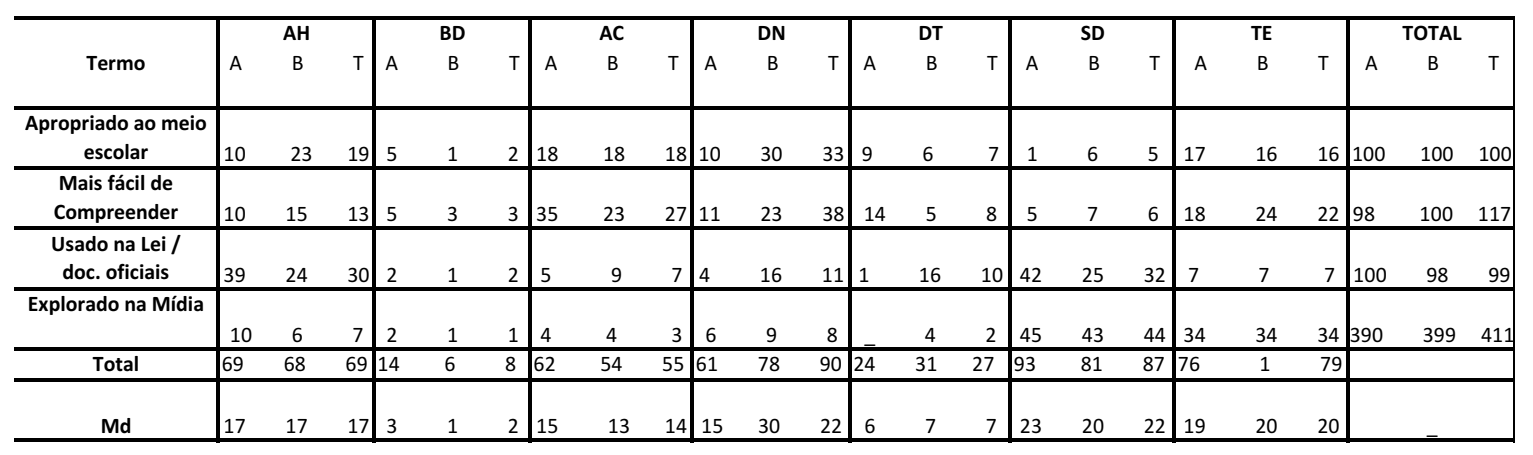

AH: Altas Habilidades; BD: Boa Dotação; AC: Alta Capacidade; DN: Desempenho Notável; DT: Dotação; SD: Superdotação; TE: Talento; Md: média

Mais uma vez, os padrões de resultados são similares nos grupos A e B, com possível disparidade em que o Grupo B, mas não o A, aponta altas habilidades como termo apropriado ao meio escolar $(\mathrm{pA}=0.102 ; \mathrm{pB}=$ 0.231; IC: [0.040 a 0.218], $\mathrm{p}=0.0046$ ); e dotação como termo usado em leis e documentos oficiais ( $\mathrm{pA}=0.010 ; \mathrm{pB}=0.242$; IC: [0.155 a 0.309$], \mathrm{p}=$ 0.0000). Por sua vez, o Grupo A diferencia dotação como fácil de compreen$\operatorname{der}(\mathrm{pA}=0.143 ; \mathrm{pB}=0.047 ; \mathrm{IC}:[0.011$ a 0.181$], \mathrm{p}=0.0275) . \mathrm{O}$ maior nível de consenso em ambos os grupos está ao redor do termo superdotação como o mais explorado pela mídia, e usado na legislação, e a expressão desempenho notável como apropriado ao meio escolar. Segue-se talento, na exploração pela midia, nos dois grupos ( $\mathrm{pA}=0.341 ; \mathrm{pB}=0.336$; IC: [-0.121 a 0.131], $\mathrm{p}=0.9357)$, e alta capacidade como mais fácil de compreender $(\mathrm{pA}=0.351 ; \mathrm{pB}$ $=0.161$; IC: [0.068 a 0.311], $\mathrm{p}=0.0023$ ). Na hipótese de a menor frequência representar possível consenso por não uso, os termos que não parecem apropriados ao meio escolar seriam boa dotação e superdotação. 


\section{Rejeição}

No propósito de averiguar sinais de rejeição pelo termo, um fator algumas vezes apontado para justificar a terminologia, foram alinhadas as afirmações-não é uma noção muito clara; leva a rotulação; traz mais rejeição, como indicadores de opinião francamente desfavorável.

Os resultados estão no Quadro 4.

\section{QUADRO 4}

Opinião sobre Rejeição

\begin{tabular}{|c|c|c|c|c|c|c|c|c|c|c|c|c|c|c|c|c|c|c|c|c|c|c|c|c|c|}
\hline \multirow[b]{2}{*}{ Termo } & \multicolumn{3}{|c|}{ AH } & \multicolumn{3}{|c|}{ BD } & \multicolumn{4}{|c|}{ AC } & \multicolumn{3}{|c|}{ DN } & \multicolumn{3}{|c|}{ DT } & \multicolumn{3}{|c|}{ SD } & \multicolumn{4}{|c|}{ TE } & \multicolumn{2}{|c|}{ TOTAL } \\
\hline & A & B & T & A & B & T & A & & B & $\mathrm{T}$ & A & B & T & A & B & $\mathrm{T}$ & A & B & $\mathrm{T}$ & & A & B & T & A & B \\
\hline \multirow[t]{2}{*}{ Não é Claro } & & & & & & & & & & & & & & & & & & & & & & & & & \\
\hline & 19 & 14 & 15 & 25 & 27 & 26 & 6 & & 7 & & 6 & 4 & & 8 & 24 & 18 & 28 & 22 & 26 & 6 & & 2 & \begin{tabular}{l|l}
3 & 9 \\
9
\end{tabular} & 98 & 100 \\
\hline \multirow[t]{2}{*}{ Leva à Rotulação } & & & & & & & & & & & & & & & & & & & & & & & & & \\
\hline & 12 & 1 & 5 & 7 & 1 & 3 & 4 & & 5 & & 7 & 3 & 5 & 4 & 8 & 6 & 52 & 69 & 65 & 8 & & 12 & $10 \quad 9$ & 94 & 99 \\
\hline \multirow[t]{2}{*}{ Traz Rejeição } & & & & & & & & & & & & & & & & & & & & & & & & & \\
\hline & 10 & 8 & 9 & 9 & 9 & 9 & 5 & & 8 & & 5 & 3 & & 6 & 12 & 10 & 48 & 53 & 57 & 1 & & 7 & \begin{tabular}{l|l}
5 & 8 \\
\end{tabular} & 84 & 100 \\
\hline Total & 51 & 23 & 29 & 41 & 37 & 38 & 15 & & 20 & 18 & 18 & 10 & 14 & 18 & 44 & 34 & 128 & 144 & 148 & 15 & 21 & 1 & \begin{tabular}{l|l}
18 & 2 \\
\end{tabular} & 276 & 299 \\
\hline Md & 17 & 7,5 & 9,5 & 13,5 & 2 & 12, & 5 & & 6,5 & 6 & 6 & 3 & 4,5 & 6 & 14,5 & 11 & 42,5 & 48 & 49 & 5 & 7 & 7 & 6 & & \\
\hline
\end{tabular}

AH: Altas Habilidades; BD: Boa Dotação; AC: Alta Capacidade; DN: Desempenho Notável; DT: Dotação; SD: Superdotação; TE: Talento; Md: média

Os resultados são também muito próximos nos dois grupos, com possível exceção de que o Grupo B opina que dotação não é muito claro e o Grupo A acha que altas habilidades leva à rotulação $(\mathrm{pA}=0.115 ; \mathrm{pB}=$ 0.008; IC: [0.038 a 0.176], $\mathrm{p}=0.0024)$. Quanto à rejeição, ambos os grupos opinam que boa dotação não é um termo claro, mas o ponto de maior realce, talvez o padrão de respostas mais visível em todo o estudo, é a opinião, em ambos os grupos, de que superdotação leva à rotulação, traz mais rejeição $\mathrm{e}$ não é um termo claro. Ao se tomar a menor porcentagem como sinal de que não parece causar rejeição, desenha-se outro padrão: boa dotação e alta capacidade não levam à rotulação, enquanto desempenho notável e talento não causam rejeição, com proporção ligeiramente maior para o grupo $\mathrm{B}$ de que talento causa rotulação $(\mathrm{pA}=0.080 ; \mathrm{pB}=0.124 ; \mathrm{IC}:[-0.038$ a 0.125$], \mathrm{p}=0.2980)$. 


\section{Estudo diferenciado de cada termo}

Superdotação - foi o termo mais utilizado por todos os sujeitos e o que desenha a configuração mais clara: Em relação à conceituação a maior frequência está agrupada na opinião de que não é um termo muito claro; quanto ao consenso pelo uso, em que é mais explorado pela mídia, seguido de que está na legislação e em documentos oficiais. No que concerne à rejeição, é apontado que leva à rotulação e traz mais rejeição.

Talento - foi o segundo termo mais utilizado por ambos os grupos. Com relação à conceituação, os dados refletem a ambiguidade encontrada na área, destacando talento como algo que a pessoa traz ao nascer e, secundariamente, que é desenvolvido pelo ambiente; o Grupo A reforça a ideia, pela afirmação de que depende de ensino, treino $(\mathrm{pA}=0.261 ; \mathrm{pB}=0.078 ;$ IC: [0.083 a 0.283], $\mathrm{p}=0.0003)$. Verificamse algumas diferenças significantes de respostas entre os grupos, isto é, o Grupo A (envolvidos e/ou interessados na área) não considera o termo fácil de compreender, $9 \%(\mathrm{pA}=0.182 ; \mathrm{pB}=0.242$; IC: $[-0.050$ a 0.170$], p=0.2876$ ); ao passo que o Grupo B (professores do Ensino Básico) não pensa em talento como desenvolvido pelo ambiente 10\%, $(\mathrm{pA}=0.422 ; \mathrm{pB}=0.180 ; \mathrm{IC}:[0.117$ a 0.366], $\mathrm{p}=0.0002)$. Com relação ao consenso pelo uso, configura-se como um termo explorado pela mídia; todavia, mostra ser bem-aceito, sem indicação de que sugira rejeição.

Altas Habilidades - quanto ao conceito, como ideário que sustenta a expressão, efetivamente não havia uma opção que pudesse ser analisada em termos de base conceitual porque não foi encontrada qualquer referência na literatura. Entretanto, se estivermos dispostos a isolar o adjetivo altas, verifica-se que a conceituação se aplica ao termo babilidade, amplamente documentado na literatura: depende de ensino e treino e é desenvolvido pelo ambiente; o Grupo A parece ter maior consciência de que esse conceito não está claro $(10 \%)$ do que o Grupo B (8\%) (pA = $0.172 ; \mathrm{pB}=0.135$; IC: [-0.061 a 0.135], $\mathrm{p}=0.4602)$. Quanto ao consenso pelo uso, a incidência maior está em ser usado em legislação e documentos oficiais - para ambos os grupos ( $\mathrm{pA}=0.388 ; \mathrm{pB}=0.242$; IC: [0.024 a 0.267], $\mathrm{p}=0.0191)$ - e apropriado ao ambiente escolar - pelo Grupo B (pA $=0.102 ; \mathrm{pB}=0.231 ; \mathrm{IC}:[0.040$ a 0.218$], \mathrm{p}=0.0046)$. Não há nenhuma indicação convincente de que o termo causa rejeição. 
Desempenho notável - essa expressão foi incluída, apesar de não levantar dúvidas quanto à diferenciação conceitual, para ajudar a captar clareza no conceito de talento, segundo o referencial em que se baseia o estudo. A configuração dos dados não deixa dúvida: desempenho notável é um conceito estabelecido em coerência com o referencial como dependente de ensino e treino e desenvolvido pelo meio ambiente; quanto ao consenso de uso, é apropriado ao meio escolar sem indicação de que causa rejeição.

Alta capacidade - essa expressão foi incluída também para sondar se o palavreado usado ou rejeitado seria uma simples questão de semântica, sem influência na conceituação, ou seja, alguns autores preferem um termo, outros preferem outro... Se o conceito estivesse claro, a diferença se limitaria a nuances da tradução. Porém, os dados não se comportam assim. Com relação à conceituação, não há uma configuração clara, mas sobre consenso pelo uso, é um conceito fácil de compreender, e pode ser visto como apropriado ao ambiente escolar, sem indicação de que causa rejeição. Não obstante, como a lei enfatiza altas habilidades, cabe especular que talvez o palavreado esteja obscurecendo o conceito de alta capacidade e, assim, alguns pensam que pode ser desenvolvida por ensino e treino... (como as habilidades)... Esse resultado também sugere que tradução imprópria, mesmo oficialmente adotada, pode confundir um conceito!

Dotação - está clara a ideia de que o conceito de dotação é coerente com o referencial deste estudo, em ambos os grupos: algo que a pessoa traz ao nascer, contudo, existe alguma incoerência em relação ao consenso, em que esse termo não é muito claro, para o Grupo B $(24 \%)-(\mathrm{pA}=$ $0.080 ; \mathrm{pB}=0.241 ; \mathrm{IC}:$ [0.068 a 0.253], $\mathrm{p}=0.0007$ ), o que pode indicar consciência de carência de conhecimento; quanto à rejeição, para o Grupo $\mathrm{A}$, o termo é fácil de compreender $(\mathrm{pA}=0.143 ; \mathrm{pB}=0.047$; IC: $[0.011 \mathrm{a}$ 0.181], $\mathrm{p}=0.0275)$, enquanto o Grupo $\mathrm{B}$ opina que o termo está nos documentos oficiais $(\mathrm{pA}=0.010 ; \mathrm{pB}=0.164$; IC: [0.087 a 0.221], $\mathrm{p}=$ 0.0000), o que efetivamente não se verifica. Por que diriam isso? Receio de mostrarem desconhecimento ou efetivo desconhecimento da legislação?

Boa dotação - conforme previsto, esse foi talvez o termo menos utilizado, em ambos os grupos. Os dados indicam que, na conceituação geral, a expressão não é um termo muito claro, no que vem implícito um grau de rejeição; nada é visto em relação ao consenso pelo uso. Há, popularmente, quem afirme que essa expressão seria usada, na gíria, para designar um pênis avantajado, o que talvez possa estar à raiz da ideia de rejeição. 


\section{Considerações finais}

O fato de haver pouca diferença entre as duas amostras leva a crer que, efetivamente, existem dificuldades generalizadas, em nossos meios, em manter uma conceituação coerente com o conhecimento acumulado, conforme explicitado no referencial teórico básico ao estudo. Para os autores, confirma-se a estranheza inicial quanto à ubíqua situação de que o termo superdotação, notavelmente representado como sem clareza de conceituação, seja amplamente empregado nas leis que regulamentam o contexto escolar, difundido para a mídia e usado nos meios acadêmicos.

Pode-se conviver com a conceituação ambígua do termo talento, por ser uma discussão presente no cenário teórico mundial, embora a falta de diferenciação entre conceitos como dotação e talento seja vital para compreender a inter-relação de capacidade natural e capacidade adquirida. Reconhecido isso, permanece o fato de que a consequência é a mesma: tal falta de diferenciação dificulta o planejamento educacional, na tomada de decisão sobre planos educativos com base em educação formal, apropriado para desenvolver talento, visto como uma expressão de valoração do ambiente; ou em ambiente educativo informal, necessário para desenvolver dotação, concebida como fonte de capacidade natural que torna possível desenvolver os talentos. 


\section{Legislação consultada}

BRASIL. Decreto n. 5.151, de 22 de julho de 2004. Disponível em: http:/ /www.receita.fazenda.gov.br/Legislacao/Decretos/2004/dec5151.htm. Acesso em: 19 jul. 2011.

BRASIL. Ministério da Educação. Secretaria de Educação Especial. Parecer CNE/CEB n. 13/2009, aprovado em 03 de junho de 2009. Brasília: MEC/SEESP, 2009a. Disponível em: http:/ / portal.mec.gov.br/index.php?option=com_content\&view=article\&id=12745\&It emid=866. Acesso em: 23 jun. 2011.

BRASIL. Ministério da Educação. Secretaria de Educação Especial. Resolução CNE/CEB 04/2009, aprovada em 02 de outubro de 2009. Brasília: MEC/SEESP, 2009b. Disponível em: http://portal.mec.gov.br/index.php?option $=$ com_content\&view $=$ article\&id $=13684 \% 3$ Aresolucoes-ceb-2009\&catid $=323 \% 3$ Aorgaos-vinculados\&Itemid $=866$. Acesso em: 23 jun. 2011.

BRASIL. Ministério da Educação. Secretaria de Educação Especial. Decreto 6.571 de 17 de setembro de 2008. Brasília: MEC/SEESP, 2008.

BRASIL. Ministério da Educação. Políticas públicas para as altas habilidades/superdotação. Brasília: Ministério da Educação - Secretaria de Educação Especial, 2007. Disponível em: www.senado.gov.br/sf/comissoes/CE/AP/AP20080626_superdotados_Cl\%C3\%A1ud iaGriboski.pdf. Acesso em: 08 ago. 2009.

\section{Referências}

ANGOFF, W. The Nature: Nurture Debate, Aptitudes, and Group Differences. American Psychologist, [S.1], v. 43, n. 9, p. 713-720, 1988.

ANTIPOFF, H. A educação do bem dotado. Rio de Janeiro: SENAI, 1992. (Coletânea de Obras Escritas de Helena Antipoff).

CHARNESS, N. Explaining exceptional performance: Constituent abilities and touchstone phenomena. Behavioral and Brain Sciences, [S.1.], v. 21, p. 410-11, 1998.

CRAWFORD, C. George Washington, Abraham Lincoln, and Arthur Jensen: Are they comparable? American Psychologist, [S.1.], v. 34, p. 664-72, 1979.

CUPERTINO, C. (Org.). Um olhar para as altas habilidades: construindo caminhos. São Paulo: FDE, 2008.

ERICSSON, K. A. The search for general abilities and basic capacities. In: STERNBERG, R. J.; GRIGORENKO, E. L. (Org.). The psychology of abilities, competencies, and expertise. Cambridge, UK: Cambridge University Press, 2003. p. 93-125.

ERICSSON, K., RORING, R.; NANDAGOPAL, K. Giftedness and evidence for Reproducibly superior performance: an account based on the expert-performance framework. High Ability Studies, [S.1.], v. 18 n. 1, p. 3-56, 2007.

GAGNÉ, F. My convictions about the nature of human abilities, gifts and talents. Journal for the Education of the Gifted, [S.1.], v. 22, p. 109-136, 1999.

GAGNÉ, F. Transforming Gifts into Talents: The DMGT as a Developmental Theory. High Ability Studies, [S.1.], v. 15, n. 2, p. 119-147, 2004.

GAGNÉ, F. From gifts to talents: The DMGT as a developmental model. In: STERNBERG,

R.; DAVIDSON, J. (Org.). Conceptions of giftedness. 2 ed. New York: Cambridge University 
Press, 2005. p. 98-119.

GAGNÉ, F. Debating giftedness: Pronat vs. Antinat. In L. Shavinina (Ed.), Handbook of Giftedness, Chapter 7, Springer. 2009.

GAGNÉ, F. Building gifts into talents: Detailed overview of the DMGT 2.0. In B. MacFarlane, \& T. Stambaugh, (Eds.), Leading change in gifted education: The festschrift of Dr. Joyce VanTassel-Baska. Waco, TX: Prufrock Press, 2009.

DAVIDSON, J. Debating giftedness: Pronat vs. Antinat. In: SHAVININA, L. (Org.). Handbook of Giftedness. [S.l.]: Springer, 2009. [Chapter 7.]

GARDNER, H. Frames of mind: the theory of multiple intelligences. New York: Basic Books, 1983.

GOLEMAN, D. Emotional intelligence. New York: Bantam Books, 1995.

GUENTHER, Z. Capacidade, Dotação e Talento: É Saber que orienta Fazer! Belo Horizonte: Editora UFMG, 2010. Parte II, p. 314-335. (Coleção Didática e Prática de Ensino, v. 3).

HOWE, M.; DAVIDSON, J.; SLOBODA, J. Innate talents: Reality or myth? Behavioral And Brain Sciences, [S.1.], v. 21, p. 399-442, 1998.

LEHMANN, A. Historical increases in expert performance suggest large possibilities for improvement of performance without implicating innate capacities. Behavioral and Brain Sciences, [S.1.], v. 21, p. 419-20, 1998.

MCCRAE, R. et al. Nature over nurture: Temperament, personality, and life span development. Journal of Personality and Social Psychology, [S.1.], v. 78, n. 1, p. 173-186, 2000.

MONTE, F. R; SANTOS, I. B. Saberes e práticas da inclusão: altas habilidades/superdotação Brasília: MEC, SEESP, 2004.

PERIPOLLI, A.; OLIVEIRA, M. P.; SANTOS, S.; FREITAS, S. N. Superdotação: (Re)significações possíveis sobre as práticas pedagógicas pela via do sensível olhar pensante. Revista de Educação do IEAU, [S.l.], v. 4, n. 9, p. 1-14, 2009.

PIECHOWSKI, M. M. Emotional and spiritual giftedness. In: COLANGELO, N.; DAVIS, G. A. (Org.). Handbook of gifted education. Boston: Allyn \& Bacon, 2003. p. 403-416. PLOMIN, R. Developmental behavioral genetics. Child Development, [S.1.], v. 54, p. $253-$ 59, 1983.

PLOMIN, R. Genetic influence and cognitive abilities. Behavioral and Brain Sciences, [S.l.], v. 21, n. 3, p. 420-421, 1998.

PLOMIN, R; PRICE, T. S. The relationship between genetics and intelligence. In: COLANGELO, N.; DAVIS, G.A. (Org.) Handbook of gifted education. Boston: Allyn and Bacon, 2003. p. 113-123.

POCINHO, M. Superdotação: Conceitos e Modelos de Diagnóstico e Intervenção Psicoeducativa. Revista Brasileira de Educaşão Especial, [S.l.], v. 15, n. 1, p. 3-14, jan.-abr. 2009. STARKES, J.; HELSEN, W. Practice, practice, practice: is that all it takes? Behavioral Brain Sciences, [S.1.], v. 21, p. 425, 1998.

STERNBERG, R. WICS as a Model of Giftedness. High Ability Studies, [S.1.], v. 14, n. 2, p. 109-137, 2003.

TESCH-RÖMER, C. Attributed talent is a powerful myth. Behavioral and Brain Sciences, [S.1.], v. 21, p. 427, 1998. 


\section{APÊNDICE 1}

\section{UMA EXPERIÊNCIA DE LEVANTAMENTO DE OPINIÃO}

\section{Os termos e expressões}

Altas habilidades - Boa dotação - Capacidade elevada - Desempenho notável Dotação - Superdotação - Talento são usados amplamente na área de educação especial, como também o são as afirmações abaixo relacionadas.

Dê sua opinião: Marque a que termo, ou termos, se aplica cada uma das afirmações:

\section{1 - É mais apropriado ao meio escolar}

Altas Habilidades - Boa dotação - Capacidade elevada - Desempenho notável Dotação - Superdotação - Talento

2 - Refere-se mais ao que a pessoa traz consigo ao nascer

Altas Habilidades - Boa dotação - Capacidade elevada - Desempenho notável Dotação - Superdotação - Talento

3 - É mais fácil de compreender

Altas Habilidades - Boa dotação - Capacidade elevada - Desempenho notável

Dotação - Superdotação - Talento

4 - É desenvolvido mais pelo ambiente

Altas Habilidades - Boa dotação - Capacidade elevada - Desempenho notável

Dotação - Superdotação - Talento

5 - Não é uma noção muito clara

Altas Habilidades - Boa dotação - Capacidade elevada - Desempenho notável

Dotação - Superdotação - Talento

6 - Depende mais de ensino e treino

Altas Habilidades - Boa dotação - Capacidade elevada - Desempenho notável

Dotação - Superdotação - Talento

7 - É usado mais pela legislação e documentação oficial

Altas Habilidades - Boa dotação - Capacidade elevada - Desempenho notável

Dotação - Superdotação - Talento 8 - Leva mais à rotulação

Altas Habilidades - Boa dotação - Capacidade elevada - Desempenho notável

Dotação - Superdotação - Talento

9 - É mais explorado pela mídia

Altas Habilidades - Boa dotação - Capacidade elevada - Desempenho notável

Dotação - Superdotação - Talento

10 - Traz geralmente mais rejeição

Altas Habilidades - Boa dotação - Capacidade elevada - Desempenho notável

Dotação - Superdotação - Talento

(Se quiser comentar, use o verso da folha). 


\section{Notas}

${ }^{1}$ Em português, gift significa "presente", "dádiva"; no sentido usado em inglês, uma tradução literal seria "dom".

2 Teste de proporção entre duas amostras independentes (pA e pB) com intervalo de confiança de $95 \%$ e nível de significância de 5\%.

Recebido: $16 / 11 / 2010$

Aprovado: 29/09/2011

Contato:

Associação de Pais e Amigos para Apoio ao Talento

Direção Técnica

Centro Para Desenvolvimento do Talento - Cedet

Rua Benedito Valadares, 187

Centro

CEP $37200-000$

Lavras, MG

Brasil 